\title{
CITRA GLOBAL LOKAL DALAM KERAMIK: Penerapan Motif Sasirangan Pada Bentuk Tas Furla
}

\author{
Sheilla Sonia
}

\begin{abstract}
Life style mostly influenced from environtment factor and give a big impact to people's consume behaviour. From so many products, bag is a useful thing that always used by human, not only as a wearable thing or fashion accessories but also a symbol of life style.

Furla bag is a global bag and become the symbol life style. This artwork's creation process was began from studying about global icon which is Furla bag, and local icon such as Sasirangan motif from semiothic method. Global and local met with creative transgression principe to create a new artwork. Both of them collaborated into ceramic artwork through some steps such as observation to shopping centers where solg bags. And then sketching process that created from stoneware. Used techniques are slib casting, slab, gores, and tempel.

The final artworks are all ceramics that can used to interior accessories. This artworks's aim are to remembering Banjar environtment to always keep traditional sasirangan motif as a culture heritage.
\end{abstract}

Keywords : Furla bag, Sasirangan, Ceramics

ABSTRAK

Gaya hidup yang banyak dipengaruhi oleh faktor lingkungan sekitar dan memberi andil besar dalam penciptaan perilaku konsumsi manusia, dari berbagai macam produk gaya hidup tas merupakan benda yang selalu melekat pada diri wanita, tas juga tidak hanya sekedar benda pakai yang hanya sebagai pelengkap dalam berbusana, akan tetapi tas bisa menjadi simbol gaya hidup bagi seseorang.

Tas Furla merupakan tas global dan menjadi salah satu simbol gaya hidup. Proses penciptaan karya ini diawali dengan mengamati tanda-tanda global yaitu tas Furla dan tandatanda lokal motif Sasirangan melalui metode semiotika yang mana global dan lokal dipertemukan dengan menggunakan prinsip creative transgression agar menciptakan sebuah karya baru. Keduanya dikolaborasikan kedalam karya seni kriya keramik melalui beberapa langkah yaitu penggumpulan data dengan cara observasi ke pusat perbelanjaan yang menyediakan toko-toko tas, pembuatan sketsa, kemudian diwujudkan kedalam karya keramik dengan menggunakan bahan baku tanah liat Stoneware. Teknik yang digunakan pada penciptaan karya ini yaitu teknik slib casting, teknik slab, teknik gores, dan teknik tempel.

Karya yang dihasilkan dalam Tugas Akhir ini berwujud karya seni kriya keramik fungsinya dapat dijadikan sebagai aksesoris interior. Karya Tugas Akhir ini tentunya bertujuan untuk mengingatkan masyarakat Banjar khususnya agar tetap terus menjaga dan melestarikan peninggalan budaya yakni motif Sasirangan sebagai warisan budaya yang harus tetap dijaga.

Kata kunci :Tas Furla, Sasirangan, Keramik

*) Sheilla Sonia, Mahasiswa Program Studi S-1 Kriya Seni Jurusan Kriya, Fakultas Seni Rupa, Institut Seni Indonesia Yogyakarta. 


\section{PENDAHULUAN}

Latar Belakang Penciptaan

Semakin maraknya masyarakat khususnya wanita yang lebih memilih produk tas bermerk dari pada produk sejenis lain yang kegunaannya sama dan berharga lebih murah, ini semua terbangun karena terkait citra diri bahwa dengan mengenakan produk bermerk maka status sosial seseorang akan terangkat. Merk adalah salah satu pertimbangan para wanita dalam membeli suatu barang salah satunya adalah tas, karena merk sering dikaitkan dengan kualitas suatu barang dan dijadikan tolak ukur barang yang akan di konsumsi. Hal semacam itu terjadi karena gaya hidup yang banyak dipengaruhi oleh faktor lingkungan sekitar yang memberi andil besar dalam penciptaan perilaku konsumtif.

Tas adalah salah satu aksesoris penting pelengkap busana bagi wanita. Berbagai bentuknya seperti tas tangan, tas jinjing, dan tas selempang. Keberadaan tas tidak dapat dipisahkan dengan kegiatan sehari-hari bagi wanita, baik wanita bekerja maupun ibu rumah tangga. Tas memiliki berbagai macam fungsi untuk dibawa ke kantor, ke acara arisan, reuni ataupun menjemput putera-puteri di sekolah. Banyak kreasi dapat dilakukan untuk membuat penampilan tas berbeda melalui pemilihan warna, bahan dan aplikasi lainnya. Benda yang satu ini tidak luput dari serbuan para kaum wanita. Terbukti dengan koleksi tas dari merk-merk terkenal dengan harga selangit, tetap dibeli para penggemarnya, dan pada era saat ini tas sudah bisa disebut sebagai simbol status sosial seseorang salah satunya adalah tas dengan merk Furla.

Melihat fenomenologi Furla yang sekarang sedang marak diperbincangkan oleh kalangan tertentu dan keberadaanya menjadi incaran para kaum-kaum sosialita elite terutama di Eropa dan Amerika. Furla merupakan salah satu merk yang cukup populer bagi kalangan tertentu, Furla lahir di negara dengan fashion yang sangat berkembang yakni Italia.

Trend tas Furla yang sekarang menjadi perbincangan dunia menjadikan penulis terinspirasi dan merenungkan untuk membuat Tas sebagai ide penciptaan karya keramik sebagai tema karya keramik. Dari hal-hal yang sering dilihat dan dimiliki bahwa tas memiliki banyak jenis dan aksen, dan dari situ penulis ingin mengolaborasikannya antara tas Furla yang sekarang jadi perbincangan dunia dengan motif Banjar yang berasal dari tempat kelahiran penulis dan memasukkan unsurunsur sosial budaya yang terkandung di dalamnya. Selain ingin melestarikan motif Banjar penulis juga ingin mengubah pandangan kebanyakan masyarakat luas yang setiap mendengar kata Kalimantan atau Borneo selalu diidentikkan dengan Dayak, suku Dayak, ornamen Dayak, adatistiadat, dan lain sebagainya, padahal pada kenyataannya Kalimantan tidak hanya memiliki Dayak tetapi juga memiliki suku Banjar beserta adat-istiadatnya, oleh sebab itu besar keinginan penulis untuk melestarikan Budaya motif Banjar yang hampir punah dan tersingkirkan oleh budaya global dan sudah mulai dilupakan oleh generasi muda. 
Sepengetahuan penulis, belum ada seniman yang membuat karya tas keramik yang dengan sengaja memasukkan unsur lokal yaitu menerapkan motif Sasirangan sebagai identitas diri dari kebudayaan asal penulis. Maka dari itu, karya ini masih orisinil, sekalipun ada beberapa seniman yang pernah menciptakan karya yang menyerupai bentuk tas seperti pesanan dari hotel Pullman kepada seniman patung bernama Arlan Kamil, yang menggunakan media fiberglass sebagai bahan utamanya dengan ukuran 2 meter dan tidak menambahkan motif sebagai penghias pada tas tersebut, dan seniman lainnya bernama Sri Astari yang juga menggunakan fiberglass sebagai bahan utamanya dengan ukuran $1340 \mathrm{~mm} \times 600 \mathrm{~mm} \times 180 \mathrm{~mm}$, jika kita lihat lebih jauh maka akan jelas perbedaan diantara ketiganya karena penulis sendiri menggunakan bahan utama keramik dan menambahkan motif Sasirangan sebagai penghias pada bodi tas.

Setelah mencermati latar belakang di atas, penulis mencoba merumuskan pemasalahan yang penulis temukan yaitu: Bagaimana menciptakan kesan citra globallokal pada karya keramik melalui bentuk tas Furla? Selanjutnya, bagaimana karya keramik tersebut dapat difungsikan sebagai elemen dan aksesoris interior? Bagaimana motif Sasirangan dapat direvitalisasikan melalui penciptaan karya keramik? Dari tiga pertanyaan tersebut dapat mewakili permasalahan yang akan penulis uraikan nantinya dalam tujuan penciptaan.

\section{Hasil dan Pembahasan}

\section{Data Acuan}

Proses penciptaan karya ilmiah ini diperlukan data acuan mengenai tas Furla dan kain Sasirangan untuk memperoleh keakuratan dan pembuktian adanya keterkaitan dengan konsep karya sebagai bahan refrensi. Data diperoleh melalui majalah, internet, foto, sebagai berikut:

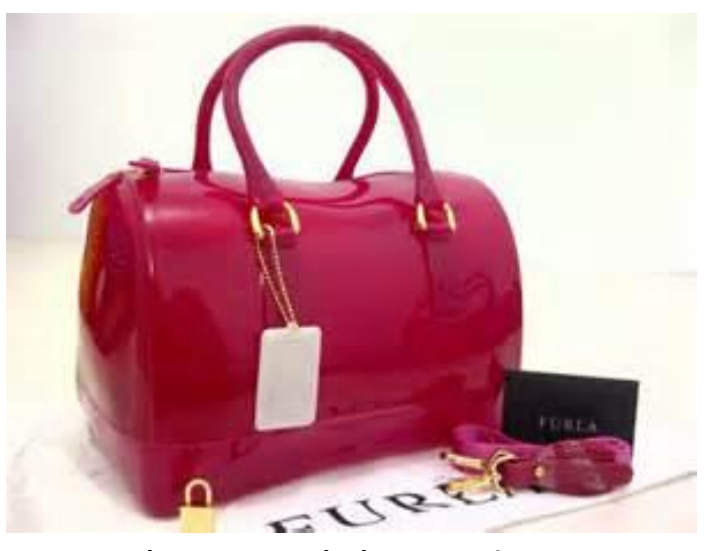

Gambar 1. Tas Furla dengan seri Dragon

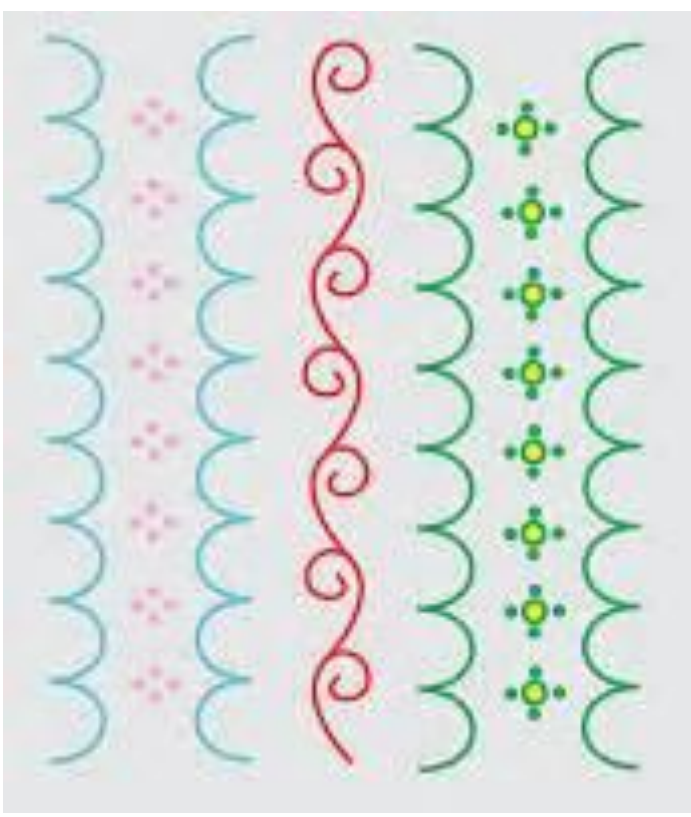

Gambar 2.Gambar diatas adalah motif Sasirangan dengan nama Bayam Raja dan Kambang Kacang

Berikut ini adalah perencanaan karya yang diawali dengan pembuatan sketsa-sketsa terpilih: 

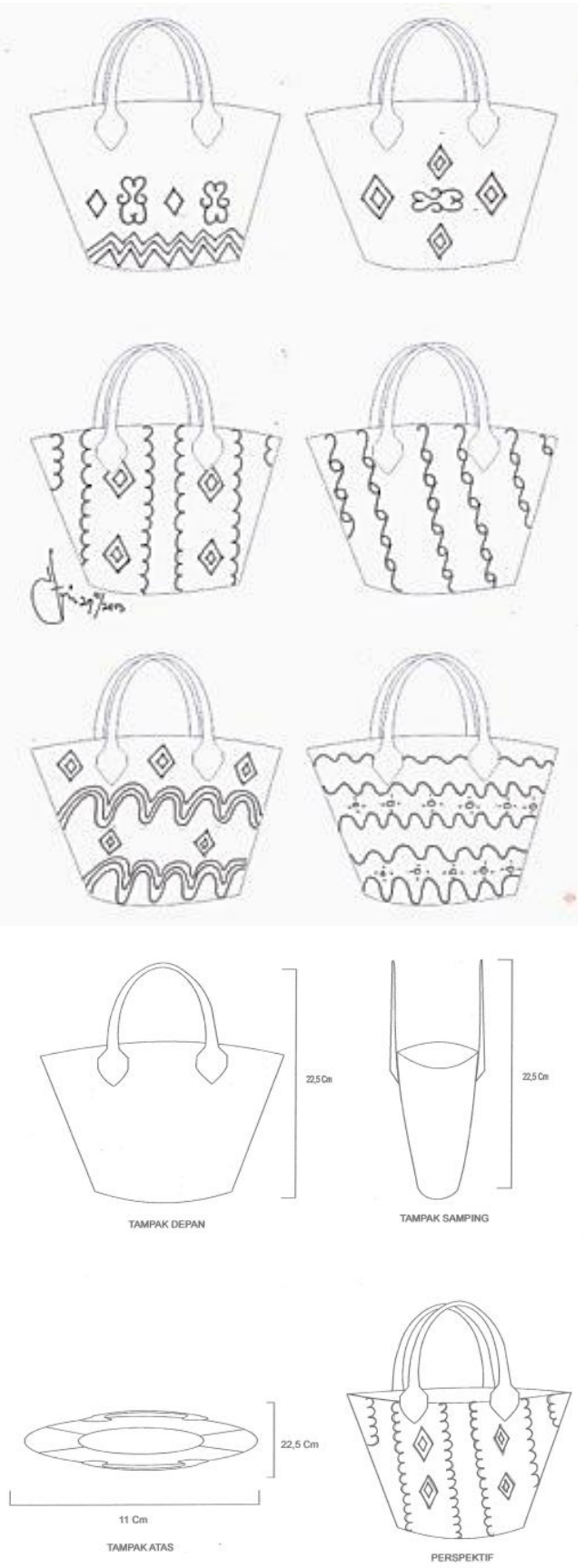

Gambar 3

Sketsa alternatif, sketsa terpilih, gambar proyeksi dan perspektif, judul karya: Komposisi Furlang 1 (Desain dan scan: Sheilla Sonia, 2013)
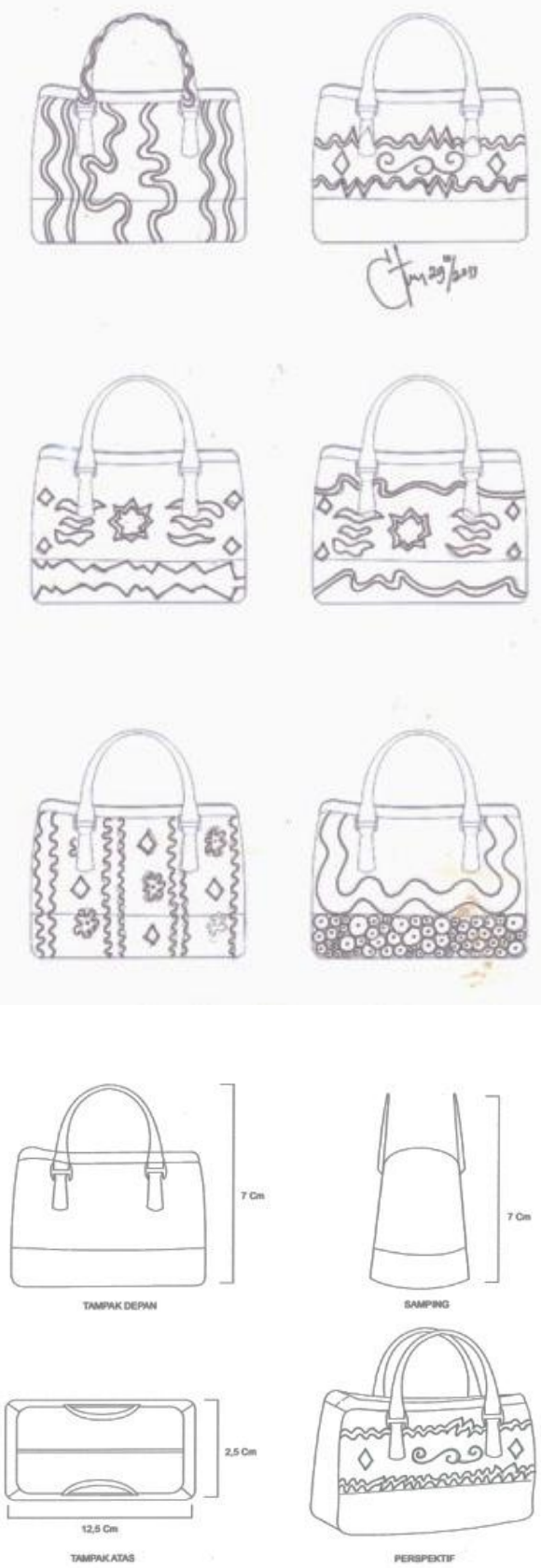

Gambar 23

Sketsa alternatif,sketsa terpilih, gambar proyeksi dan perspektif

judul karya: Komposisi Furlang \#1

(Desain dan scan: Sheilla Sonia, 20124) 

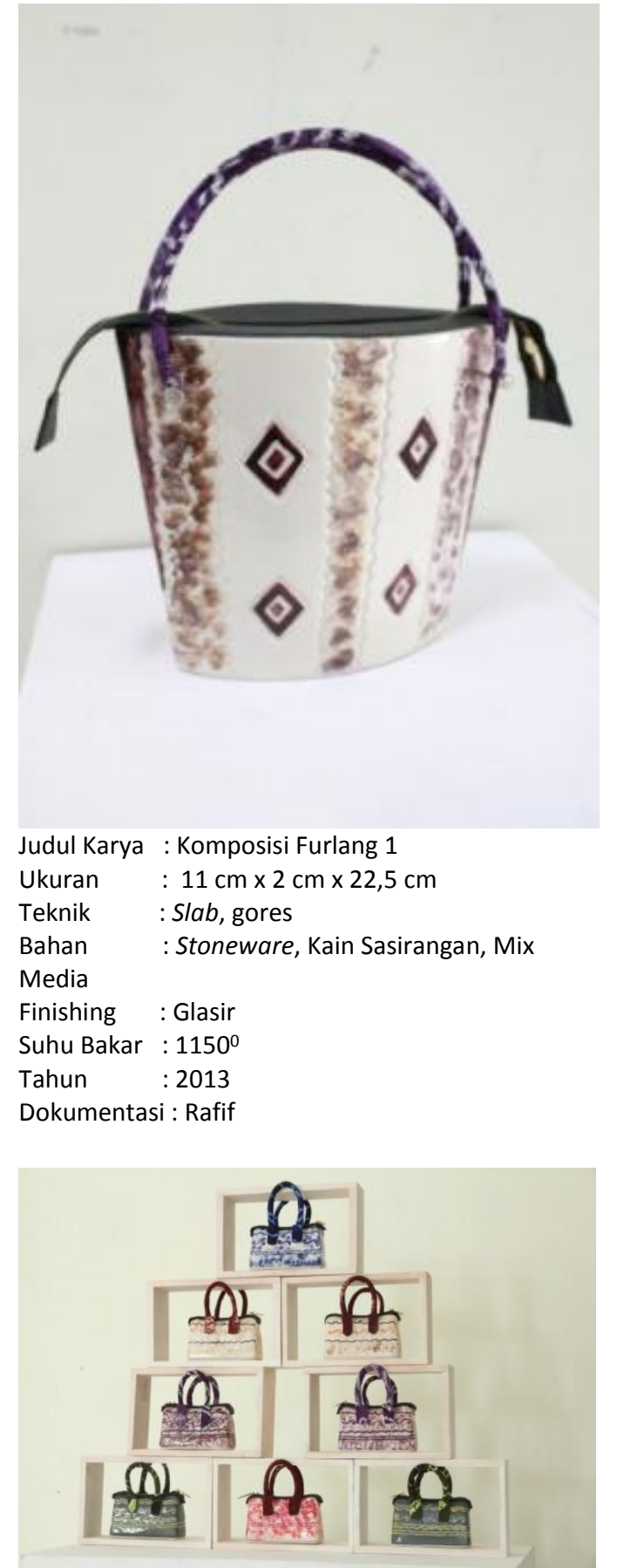

Judul Karya : Komposisi Furlang \#1 Ukuran : $12 \mathrm{~cm} \times 2,5 \mathrm{~cm} \times 7 \mathrm{~cm}$ Teknik : Slib Casting (cetak tuang), gores Bahan : Stoneware, Kain Sasirangan, Mix Media Finishing : Glasir Suhu Bakar : $1150^{\circ}$

Tahun : 2014

Dokumentasi : Rafif
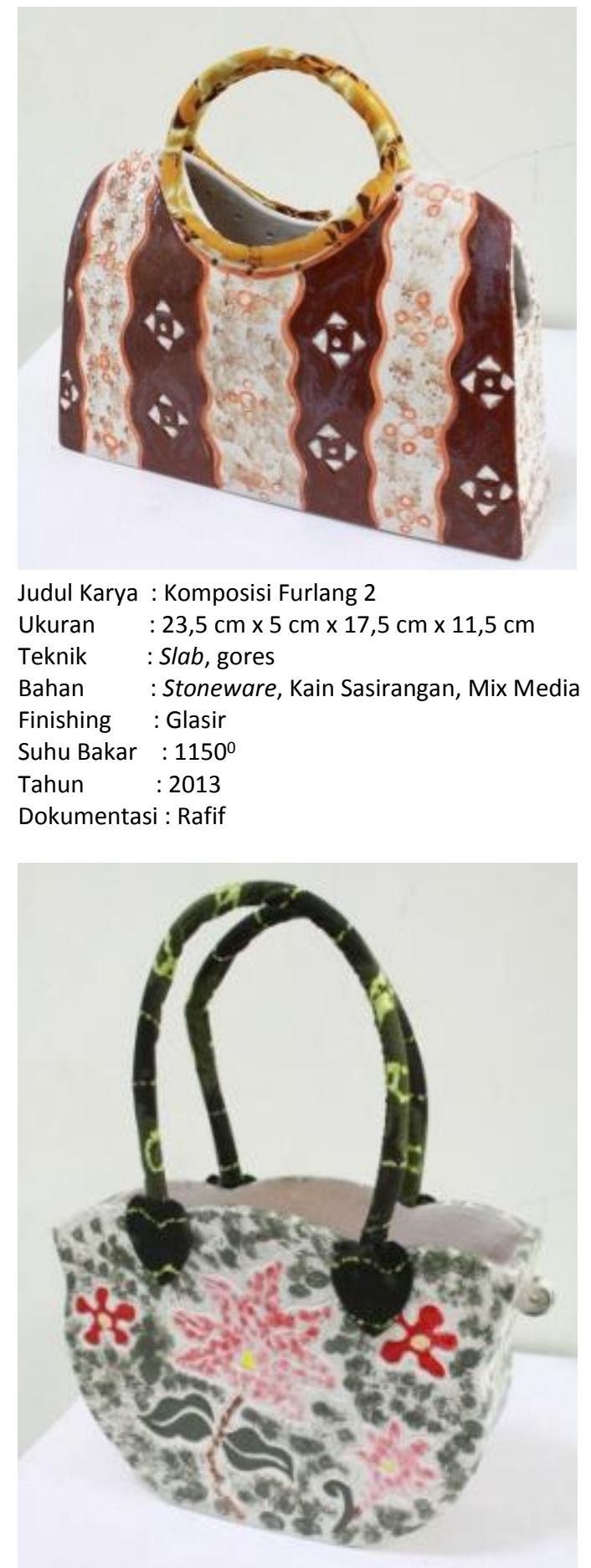

Judul Karya : Komposisi Furlang 3

Ukuran : $24,5 \mathrm{~cm} \times 8,5 \mathrm{~cm} \times 18 \mathrm{~cm}$

Teknik :Slab, gores

Bahan : Stoneware, Kain Sasirangan, Mix

Media

Finishing : Glasir

Suhu Bakar : 1150

Tahun : 2014

Dokumentasi : Rafif 


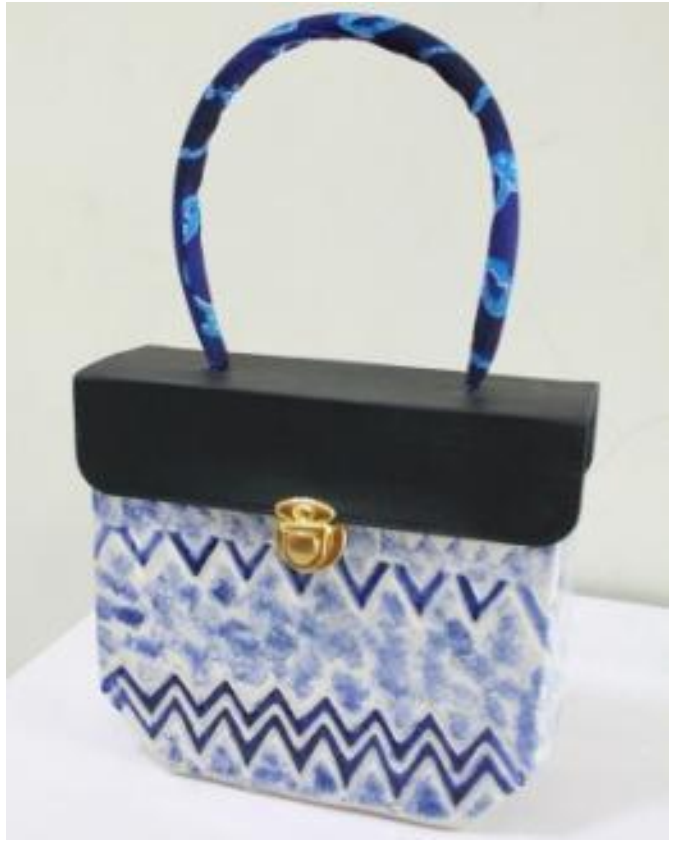

Judul Karya : Komposisi Furlang 4

Ukuran $: 21 \mathrm{~cm} \times 17 \mathrm{~cm} \times 7 \mathrm{~cm}$

Teknik :Slab, gores

Bahan : Stoneware, Kain Sasirangan, Mix

Media

Finishing : Glasir

Suhu Bakar : 1150

Tahun : 2014

Dokumentasi : Rafif

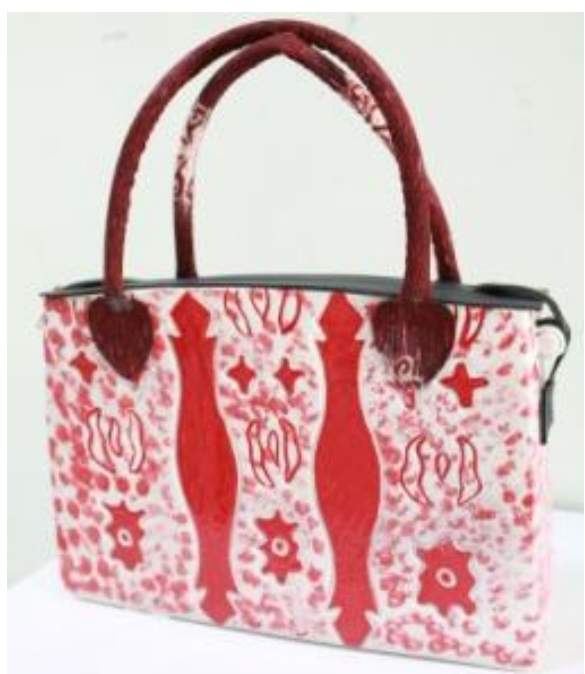

Judul Karya : Komposisi Furlang 5

Ukuran : $29,5 \mathrm{~cm} \times 8 \mathrm{~cm} \times 19,5 \mathrm{~cm}$

Teknik : Slab, gores

Bahan : Stoneware, KainSasirangan, Mix Media

Finishing : Glasir

Suhu bakar : 1150

Tahun : 2014

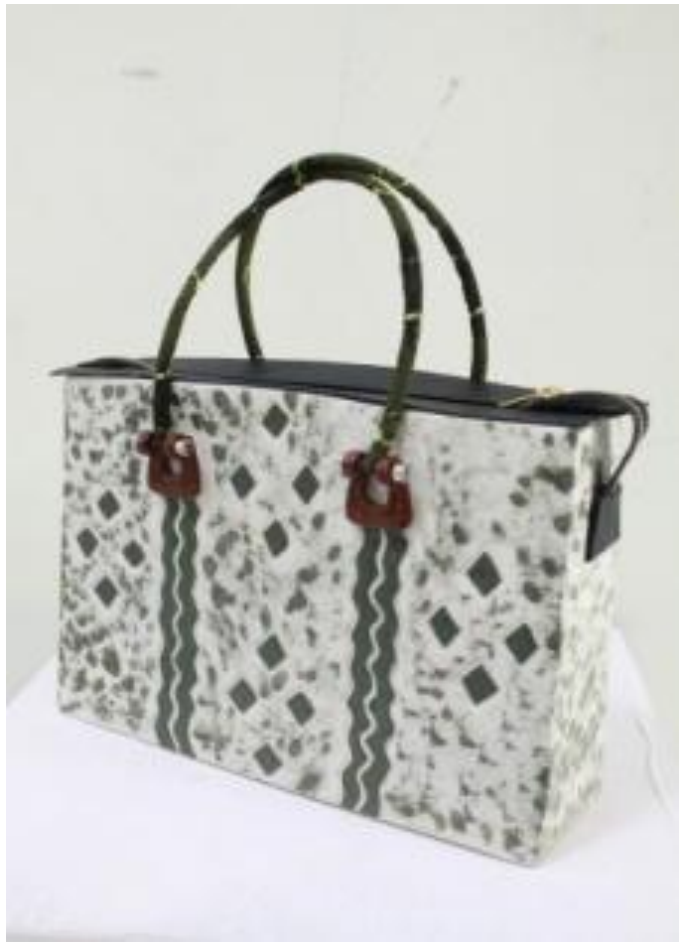

Judul Karya : Komposisi Furlang 6

Ukuran : $30 \mathrm{~cm} \times 8,5 \mathrm{~cm} \times 21 \mathrm{~cm}$

Teknik : Slab, gores

Bahan :Stoneware, Kain Sasirangan, Mix Media Finishing : Glasir

Suhu Bakar : 1150

Tahun : 2014

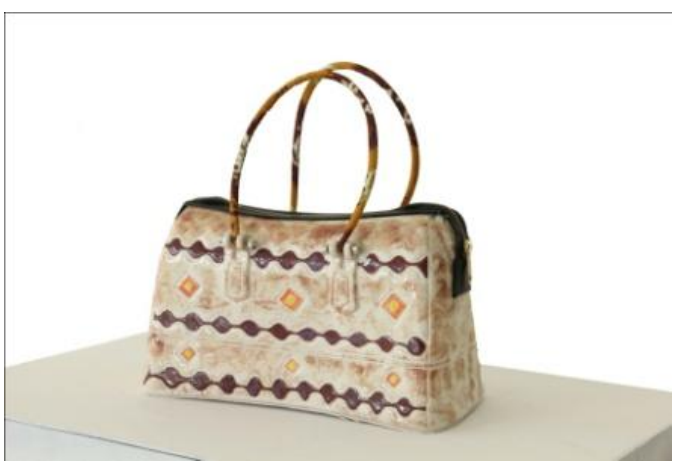

Judul Karya : Komposisi Furlang \#2

Ukuran : $29 \mathrm{~cm} \times 13 \mathrm{~cm} \times 20 \mathrm{~cm}$

Teknik : Slib Casting (cetak tuang), gores

Bahan : Stoneware, Kain Sasirangan, Mix Media Finishing : Glasir

Suhu Bakar : $1150^{\circ}$

Tahun : 2014 


\section{DAFTAR PUSTAKA}

Astuti, Ambar, Pengetahuan Keramik, Yogyakarta:Gajah Mada University Press 1997.

Barker, Chris, Cultural Studies, Yogyakarta: Kreasi Warna, 2008.

Blackbrun, Simon, Kamus Filsafat, Yogyakarta: Pustaka Pelajar, 2008.

Gustami, SP, Nukilan Seni Ornamen Indonesia, Yogyakarta: Jurusan Kriya Fakultas Seni Rupa ISI Jogja, 2008.

Raharjo, Timbul, Teko Dalam Perspektif Keramik, Yogyakarta: Tonil Press, 2001.

Sunardi, ST, Semiotika Negativa, Yogyakarta: Kanal, 2002.

Tim Penyusun Kamus, Kamus Besar Bahasa Indonesia, Jakarta: Balai Pustaka, 2005.

\section{WEBTOGRAFI}

Utomo, Agus Mulyadi, Keramik Bali Kuno, http://www.balispot.co.id, Desember, 12, 2013.

http://wordpress.com, Tas Furla, Desember, 13, 2013.

http://kainikat.com , Motif Sasirangan, Desember, 15, 2013. 